\title{
In Memoriam: Professor Kotaro Suzumura (January 7, 1944-January 15, 2020)
}

Published online: 15 April 2020

(C) Japanese Economic Association 2020

Professor Kotaro Suzumura, a distinguished scholar on social choice and welfare economics, passed away on 15 January, 2020, aged 76 . He was the president of the Japanese Economic Association from 1999 to 2000, and elected member of the Japan Academy in 2011. He played a vital role in launching Japanese Economic Review in 1995 and assumed the position of the first Editor of the Journal. He was also the president of the Society for Social Choice and Welfare from 2000 to 2001. Over the years of his distinguished career, Professor Suzumura taught at LSE, Kyoto University, Hitotsubashi University, and Waseda University.

Professor Suzumura had devoted to research on several facets of normative economics, which can be classified as (1) rational choice as rationalizable choice; (2) generalizations of Arrow's impossibility theorem; (3) individual rights and social welfare; (4) consequentialism versus nonconsequentialism; and (5) market competition and social welfare.

In the first research area, Professor Suzumura (1983) developed the general theory of rational choice and introduced Suzumura-consistency ( $S$-consistency) as the necessary and sufficient condition for binary relations that are not necessarily complete and transitive to have an ordering extension. Moreover, his work (Bossert and Suzumura 2010) and Suzumura (2016) pushed forward the theory of rational choice on general domains by means of $S$-consistency. In the second research area, Professor Suzumura showed that Arrow's impossibility theorem continues to hold even if we relax the full rationality of collective choice to some conditions for internal consistency of choice Suzumura (1983) as well as to $S$-consistent rationality in Bossert and Suzumura (2010) and Suzumura (2016). In the third area of research, Suzumura (1983) showed the resolution of Sen's impossibility of a Paretian liberal by means of the existence of a liberal individual, while Suzumura (2016) criticized Sen's articulation of individual rights and proposed the game form approach to libertarian rights as an alternative. In the fourth research area, Suzumura (2016) axiomatically characterized consequentialism and nonconsequentialism, while his work (Pattanaik and Suzumura 1996) proposed the procedural fairness approach to the initial

We thank Naoki Yoshihara for his valuable advice. 
conferment of institutions for social decision-making. Finally in the fifth area, Professor Suzumura established the renowned Suzumura-Kiyono Excess Entry Theorem (Suzumura and Kiyono 1987), a classical finding in Industrial Organization that free entry generally fails to achieve social efficiency, because entrants over-internalize the increment of total surplus. Professor Suzumura went on to analyze and evaluate Japan's post-war industrial policy in the influential monograph (Komiya et al. 1988).

Professor Suzumura is known for his elegant theoretical analysis, crystal-clear presentation, and keen interest in social justice and social philosophy. He is an eternal role model of all social scientists. We owe him deeply, and he will be sorely missed by all of us.

\section{Members of the Editorial Board}

\section{References}

Bossert, W., \& Suzumura, K. (2010). Consistency, choice, and rationality. Cambridge: Harvard University Press.

Komiya, R., Okuno, M., \& Suzumura, K. (Eds.). (1988). Industrial policy of Japan. San Diego: Academic Press.

Pattanaik, P. K., \& Suzumura, K. (1996). Individual rights and social evaluation: a conceptual framework. Oxford Economic Papers, 48(1996), 194-212.

Suzumura, K. (1983). Rational choice, collective decisions and social welfare. Cambridge: Cambridge University Press.

Suzumura, K. (2016). Choice, preferences and procedures: A rational choice theoretic approach. Cambridge: Harvard University Press.

Suzumura, K., \& Kiyono, K. (1987). Entry barriers and economic welfare. Review of Economic Studies, $54,157-167$. 